DOI 10.5216/ia.v46i2.67767

\title{
A SUBVENÇÃO ESCOLAR NO PARANÁ E A NACIONALIZAÇÃO DO ENSINO NAS ÁREAS DE IMIGRAÇÃO (1899-1938)
}

\author{
VALQuírIA ELITA RenK \\ Pontifícia Universidade Católica do Paraná (PUCPR), Curitiba, Paraná, Brasil \\ Elaine Cátia Falcade Maschio \\ Universidade de Caxias Do Sul (UCS), Caxias Do Sul, Rio Grande Do Sul, Brasil
}

\begin{abstract}
Resumo: Analisa-se a importância da subvenção escolar estadual e federal na organização da escola pública primária e nacionalização do ensino no Paraná. Os anos de 1899 a 1938 representam o período de discussões sobre a obrigatoriedade do ensino da Língua Portuguesa nas escolas subvencionadas e particulares, em função das possíveis ameaçadas provocadas pela organização escolar étnica, até a nacionalização compulsória do ensino. Havia uma disputa do espaço escolar entre o governo estadual com as comunidades étnicas e a atuação do governo federal. $O$ método histórico orienta a análise teórico metodológica, cujas fontes são os documentos oficiais como: legislação educacional, relatórios de governo, ofícios, requerimentos, jornais de circulação regional. A História Cultural lança luz sobre o corpus documental. As fontes revelam que os recursos da subvenção escolar deveriam ser direcionados às escolas elementares, mas, também foram destinados às escolas étnicas, espaços privilegiados para a formação da infância brasileira ideal. Contudo, a organização dessas escolas ocorreu de forma negociada entre autoridades de ensino e comunidade étnica para nacionalizar a infância, mas, também dentro das possibilidades manter a identidade étnica.
\end{abstract}

Palavras-chave: Escolas Étnicas. Subvenção Escola. Nacionalização do Ensino.

\section{INTRODUÇÃO}

O presente trabalho pretende discutir a importância da subvenção escolar no processo de nacionalização do ensino nas regiões de imigração no Paraná, especialmente a organização das Escolas Subvencionadas Federais. Contemplando o interim dos anos de 1899 a 1930, busca-se identificar as intenções e relações de poder na análise das estratégias dos governos estadual e federal para a instituição e fortalecimento de uma rede de escolas primárias. Almeja-se ainda identificar os sujeitos, e os conflitos gerados naquele contexto escolar considerando a atuação dos Inspetores Escolares e o papel desempenhado por eles no processo de inspeção.

Por tratar-se de uma pesquisa historiográfica, as fontes de pesquisa são a matéria prima da investigação (VEYNE, 2008). Elas foram produzidas por instituições que têm um lugar específico de enunciação, com representação social, e revelam-se como instrumentos de poder, de verdade, com significação política e histórica (NEGREIRO; DIAS, 2002; DERRIDA, 2001). As fontes documentais são essenciais na pesquisa historiográfica, pois trazem os "vestígios de suas ações e interferência, pode nos 
proporcionar um acesso significativo à compreensão do passado humano e de seus desdobramentos no presente" (BARROS, 2019, p. 15). Logo, o corpus empírico desta pesquisa foi composto por fontes documentais que correspondem a legislação educacional do Paraná, os Relatórios de Governo, além de outros documentos oficiais, como ofícios e requerimentos do poder executivo, jornais de circulação regional, os quais registram a intenção de nacionalização da infância imigrante por meio da subvenção escolar e o controle dos processos de resistência nas comunidades étnicas. Para Chartier (2002, p. 17), as práticas e as estratégias "tendem a impor uma autoridade à custa de outros, por elas menosprezadas, a legitimar um projecto reformador ou a justificar, para os próprios indivíduos, as suas escolhas e condutas". Portanto, foi necessário buscar nos arquivos governamentais, aqueles documentos que pudessem desvelar o olhar oficial, assim como, os discursos presentes nos jornais os quais revelam como as ideias circulavam. Esse cotejo das fontes permitiu compreender os processos engendrados pelo governo e pelas comunidades. O primeiro, na tentativa de nacionalizar os descendentes de imigrantes, ainda que brasileiros; e o segundo, nas empreitadas que mobilizavam resistências diante da intenção de manter a identidade cultural. Assim, entende-se que os arquivos guardam os documentos, trazem uma seleção de memória que deixam vestígios das ações. Por isso, também podem ser considerados como lugares de memória (LE GOFF, 2003, FARGE, 2009). Nesta perspectiva teórico metodológica, é o pesquisador que precisa questionar e cotejar as fontes para apreender o processo de intensificação das políticas de nacionalização da infância e juventude, através da subvenção escolar.

O Paraná emancipou-se de São Paulo em 1853. Era um estado agrícola, com grandes vazios demográficos e a população tinha baixa escolaridade com um número expressivo de analfabetos. Após 1870, com mais intensidade o governo estadual propôs a ocupação do território com população estrangeira (europeia) por meio da formação de colônias étnicas em torno de Curitiba e no interior do Paraná. Nas colônias étnicas, a comunidade construía a igreja, a escola ou a sociedade cultural/agrícola/instrucional, o cemitério e outros espaços de sociabilidade. Quando não havia escolas públicas, a comunidade ou as Congregações Religiosas assumiam a educação das crianças, a construção, manutenção da escola e pagamento do professor (RENK, 2014). Isto denota a importância da escolarização para esses grupos de imigrantes, que visualizavam na escola diferentes possibilidades de empregabilidade, adaptação social ou conservação da identidade étnica. Mas, as escolas étnicas em sua maioria existiam à margem do sistema estatal. Portanto, ensinavam os conteúdos de interesse do grupo na língua de origem da comunidade, assim como, a história e cultura do grupo. Até a Primeira Guerra Mundial, esta situação não incomodava muito as autoridades e posteriormente a esta data começaram a pautar pela nacionalização do ensino, especialmente com o ensino da Língua Portuguesa, Geografia e História do Brasil.

Para a organização e expansão do sistema público de ensino era contemplada a subvenção escolar estadual, que consistia num auxílio financeiro pago pelo governo para o pagamento de professor. A primeira menção a subvenção escolar na Província, consta na Lei 17 de 14 de setembro de 1854, artigo 10: "quando em alguma povoação ou bairro populoso, não houver o número de meninos ou meninas que justifique a 
criação de uma escola pública, o Governo poderá subvencionar um mestre particular para ensinar os meninos pobres com a gratificação anual de 120\$000" (MIGUEL; MARTIN, 2000, p. 34).

Nas primeiras décadas do século XX, a legislação educacional do Paraná enfatizava que a subvenção seria destinada às escolas, desde que ensinassem em língua nacional e que seriam fiscalizados pelas autoridades de ensino (Lei 365 de11 e abril de 1900, artigo 20) (RENK, 2004). O sentido da subvenção escolar, naquele momento era de ampliar o aparelho escolar público e aumentar a população escolarizada.

Para que o professor recebesse a subvenção do governo estadual deveria ter ao menos 20 alunos em classe e nas áreas de colonização estrangeira e ensinar em Língua Portuguesa (RENK, 2009). A subvenção também poderia ser solicitada para custear as despesas das escolas particulares que atendiam estudantes pobres. A exemplo disso pode-se citar que na Colônia Muricy, município de São José dos Pinhais, não havia escola pública, havia somente uma escola particular (escola étnica) com frequência de 150 alunos sendo 50 os que não pagavam a mensalidade. A religiosa estrangeira (polonesa) responsável pela escola solicitou a subvenção ao governo estadual, a qual foi concedida (DEAP, Ofícios, 1912, v. 26). Outra situação é a da escola étnica (polonesa) do município de Mallet, que solicitou subvenção justificando que ali se ensinava a História do Brasil e a Língua Portuguesa (DEAP, Requerimento, 1913, v. 10):

O ensino por meio de professores subvencionados vai dando bons resultados, sendo preciso que fique organizado um grupo de dedicados servidores, falando a língua nacional e com bons conhecimentos das estrangeiras, para por meio de um ensino prático e comparativo se conseguir um maior adiantamento dos alunos, e principalmente dos colonos, despreocupados do nosso evoluir, das nossas atitudes político-sociais e só pensando em retirar da terra ubérrima a sua subsistência (PARANÁ, 1913, p.16).

As fontes de pesquisa mostram que o governo estadual acreditava que, com a subvenção escolar, as crianças aprenderiam a língua nacional nas áreas de colonização estrangeira e seriam inseridas na cultura nacional. É a partir da primeira quinzena do século XX que as campanhas de nacionalização do ensino começam a se intensificar. Obrigando o ensino da língua vernácula, proibindo o ensino em língua estrangeira e fechando as escolas étnicas, o Estado alcançava as comunidades imigrantes. Além de destituir suas redes de escolas buscava implantar uma padronização do ensino público. Pelo Decreto no 13.014 de 04 de maio de 1918 o governo brasileiro instituiu as Escolas Subvencionadas Federais, as quais tinham como objetivo prover o atendimento escolar e ampliar o ensino da Língua Portuguesa nas regiões de expressiva colonização estrangeira.

O decreto fazia parte das ações expedidas em virtude da autorização contida no Decreto legislativo no 3.361, de 26 de outubro de 1917. Este último reconhecia e anunciava o estado de guerra iniciado pelo Império Alemão contra o Brasil. De acordo com Rinke (2014), as relações amistosas entre Brasil e Alemanha começaram a se desestabilizar no decorrer da Primeira Guerra Mundial, quando os navios brasileiros foram afundados por submarinos alemães. Diversas cidades brasileiras que abrigavam instituições e empresas alemãs foram afetadas. O Sul do país concentrava o maior 
número de colônias alemãs. As estratégias de cerceamento da organização estrangeira reverberaram também na organização do ensino, fazendo com que o governo investisse no fortalecimento do ensino da Língua Portuguesa, por meio da ampliação do número de escolas primárias para atenuar a atuação dos imigrantes europeus.

Interessante notar que a instituição da subvenção federal para o ensino da Língua Portuguesa nos estados advém das relações diplomáticas estabelecidas e do sentimento de ameaça que essas populações causavam ao estado brasileiro. Desse modo, foi nos estados do sul que se estabeleceram as políticas de institucionalização das Escolas Subvencionadas Federais. Enquanto o governo federal dispendia os recursos financeiros para a manutenção destas escolas e engendrava um sistema vigoroso de fiscalização, o governo estadual deveria criar a escola, equipá-la com móveis e materiais escolares, designar os professores e exigir o cumprimento do programa oficial de ensino, do horário e dos métodos de ensino, conforme aqueles determinados pelos regulamentos vigentes (PARANÁ, 1921, p. 91).

No relatório do Inspetor Geral do Ensino Cesar Pietro Martinez, no ano de 1922 havia no Paraná 116 Escolas Subvencionadas Federais. Funcionavam regularmente, 110 escolas divididas em: 12 masculinas, três femininas e 95 mistas. Como é possível observar na passagem abaixo, esse montante era distribuído em 25 municípios paranaenses:

\begin{abstract}
Antonina (1 mista); Araucária (3 mistas); Campo Largo (4 masculina, 4 mista); Colombo (1 mista); Curitiba (1 masculina, 14 mista); Entre Rios (1 mista); Guarakessaba (1 mista); Iraty (3 mistas); Lapa (5 mistas); Morretes (1 mista); Palmas (3 masculinas, 1 feminina); Palmeira (4 mistas); Paranaguá (3 mistas); Prudentópolis (8 mistas); Ponta Grossa (1 mista); Rio Negro (4 mista); Rio Branco (1 masculina, 2 mistas); São Mateus (1 feminina, 2 mistas); São José dos Pinhais (15 mistas); Santo Antônio do Imbituva (2 masculinas, 4 mistas); Tamandaré (5 mistas); Tibagy (1 mista); União da Vitória (3 mistas); Ypiranga (1 masculina, 1 feminina, 7 mistas); e Bocaiuva (1 mista) (PARANÁ, 1922, p. 58).
\end{abstract}

O número de alunos matriculados totalizava 4.198, sendo 2.425 meninos e 1.773 meninas. A frequência, porém, era de 3.052 crianças. Observou-se que a região que concentrava o maior número de escola era capital paranaense. Isso se devia ao fato de um grande número de núcleos coloniais localizado no chamado cinturão verde da cidade de Curitiba, contabilizando uma avultada cifra de famílias estrangeiras. Neste mesmo documento consta que a matrícula e a frequência das escolas eram elevadas $(78,5 \%)$ e que o número de meninas matriculadas que as frequentavam era superior ao dos meninos. Consta também que das 37 escolas estrangeiras inspecionadas em 1922, 23 seguiam o Programa Oficial de Ensino do estado do Paraná e as outras 13 escolas adotavam programa especial, mas ensinavam Português, História e Geografia do Brasil. Estas disciplinas eram consideradas pelas autoridades como fundamentais para nacionalizar o ensino e manter as verbas da subvenção. 
RENK, V. E.; MASCHIO, E. C. F.

Neste documento, o governo reconhecia que a matrícula e a frequência das escolas étnicas eram superiores às das escolas subvencionadas e que a totalidade destas era insuficiente para atender os municípios. Em relatório, o Inspetor Geral do Ensino Cesar Pietro Martinez relatava que:

\begin{abstract}
Subvenciona o Governo Federal 116 escolas creadas e mantidas pelo Governo do Estado em colônias extrangeiras, e isso com o fim de nacionalisar o filho do colono. Já tivemos opportunidade de reclamar o augmento dessas escolas, pois as que existem são insufficientes para attender as necessidades exigidas pelo augmento da população extrangeira. Tem-se interessado a Inspectoria pelo regular funccionamento desses estabelecimentos primários, inspeccionando-os a miúdo e fornecendo-lhes mobiliário e material didático. São deveras satisfactorios os resultados que a grande maioria dessas escolas apresenta. O seu concurso na disseminação do alphabeto é deveras importante (PARANÁ, 1923, p. 88).
\end{abstract}

Empreender a educação nacional e garantir o sucesso da alfabetização da Língua Portuguesa foram dois dos principais aspectos que constituíram a cultura escolar das Escolas Subvencionadas Federais do Paraná. Neste sentido, o esquema de fiscalização estadual e federal destacava-se como instrumento de controle do ensino, incidindo na organização dessa rede de escolas primárias.

\title{
A SUBVENÇÃO ESTADUAL E A REIVINDICAÇÃO PELA NACIONALIZAÇÃO DO ENSINO NO PARANÁ.
}

A prática de subvencionar escolas primárias no Paraná era justificada pela incapacidade por parte do Estado em suprir com escolas públicas à significativa parcela da população infantil em idade escolar. Essa ação era de certa forma vantajosa ao governo, pois delegava aos professores e a própria comunidade a responsabilidade pela organização das classes.

O processo de solicitação de subvenção era bastante simples. Bastava que o professor encaminhasse à Diretoria da Instrução Pública alguns documentos, especialmente expedidos pelos inspetores escolares, como aqueles que comprovassem a existência e o funcionamento da escola. A Lei no 962 de 31 de outubro de 1889 instituiu o Regulamento das Escolas Subvencionadas, bem como, estabeleceu a criação de 100 delas com um subsídio de $360 \$ 000$ reis anuais. Conforme essa legislação, as escolas subvencionadas poderiam ser promíscuas e regidas por professores sem habilitação. Uma vez ao mês, deveriam receber a visita do inspetor escolar para atestar o funcionamento da escola e o pagamento do subsídio. Caberia ao professor ministrar ao menos três horas diárias de aula, com exceção de domingos e feriados.

Quanto ao ensino, interessante observar que o Regulamento não obrigava o ensino da gramática e da geografia brasileira: "Art.8 - O ensino nas escolas subvencionadas será de leitura, escripta, das quatro operações elementares de arthmetica e religião, ficando livre aos professores o de grammatica portuguesa e de noções de geografia do Brazil" (PARANÁ, 1889). Portanto, desde a promulgação do primeiro Regulamento da Instrução Pública da Província paranaense, a subvenção 
estadual pressupunha a ampliação do número de escolas primárias. Ainda nesse momento, o estado não demostrava preocupação com a obrigatoriedade do ensino da Língua Portuguesa, sendo que muitas escolas de estrangeiros recebiam os subsídios do governo brasileiro (MASCHIO, 2012).

Foi no final do século XIX que o processo de subvenção de escolas passou a articular a obrigatoriedade da língua vernácula. A primeira legislação educacional paranaense que determinava a obrigatoriedade do ensino do português nas escolas elementares de caráter particular, com especial atenção àquelas subvencionadas pelo Estado e, consequentemente, localizadas em colônias estrangeiras, foi a Lei no 365 de 11 de abril de 1900.

Essa lei, no artigo 20 e inciso $1^{\circ}$, determinava a fiscalização das instituições escolares e a obrigatoriedade de ensinar da Língua Portuguesa nas escolas particulares, especialmente aquelas que recebiam a subvenção estatal (PARANÁ, 1900).

\begin{abstract}
Não obstante, a elaboração desta lei ocorreu após uma ampla discussão no Congresso Legislativo, iniciado ainda no ano de 1899, com projeto $n^{\circ} 10$. Esse projeto autorizava o governo a rever o Regulamento e os decretos relativos à Instrução Publica do Paraná. Foi na $22^{\mathrm{a}}$ sessão ordinária do Congresso Legislativo, que o então deputado estadual Telêmaco Borba propôs a inserção de uma emenda ao projeto instituindo a obrigatoriedade do ensino da língua vernácula em todas as escolas elementares públicas e particulares do Estado. Iniciava-se neste momento no Paraná, os discursos sobre a necessidade da nacionalização do ensino, e o papel incisivo do Estado na formação da infância estrangeira nas colônias, por meio da padronização do processo de escolarização primária (MASCHIO, 2018, p. 7).
\end{abstract}

A partir da primeira década do século XX a imprensa do Paraná registrava as tensões entre as comunidades étnicas e a sociedade brasileira, referente ao uso da língua materna pelos grupos étnicos e a exigência do ensino e uso da língua nacional. Apesar de não mencionar a subvenção escolar, a imprensa - especialmente os jornais Der Kompass e Diário da Tarde - de Curitiba foram muito atuantes na discussão sobre a nacionalização do ensino no Paraná.

As matérias jornalísticas registravam as discussões em torno da necessidade do ensino da Língua Portuguesa nas escolas para nacionalizar a infância, denunciando o ensino na língua de origem do grupo étnico nas escolas étnicas ${ }^{2}$ e clamando sobre o perigo da desnacionalização da infância. A língua materna para os descendentes de imigrantes era a língua de origem do grupo, era ensinada em suas escolas, falada nos espaços públicos da colônia, nas igrejas e publicada nos livros e jornais. Representava a manutenção da identidade cultural do grupo. Mas, as autoridades educacionais brasileiras e mesmo os políticos, começaram a demonstrar incômodo com esta situação, uma vez que muitas destas crianças eram brasileiras e pouco ou nada conheciam da língua nacional. 
RENK, V. E.; MASCHIO, E. C. F.

O jornal Der Kompass ${ }^{3}$, publicado pelos padres franciscanos de Curitiba, registou desde 1906 as tensões entre as autoridades brasileiras e as comunidades alemãs do Brasil, no que se refere ao ensino em língua alemã e o 'perigo alemão' ${ }^{4}$. Em matéria de 03 de novembro de 1906, publicou que: "Houve uma ousada investida contra as escolas alemãs no sul do Brasil. O Deputado Barbosa Lima, em sessão na Câmara do dia 25 de outubro, desenterrou a 'variação' do 'perigo alemão' que ameaçava amplificarse seriamente", propondo-se o fechamento das escolas que não ensinassem em Língua Portuguesa.

Durante a Primeira Guerra Mundial, inúmeras tensões entre comunidades étnicas, especialmente a alemã e a sociedade brasileira, foram registradas no Paraná. Desde as manifestações em praça pública, ao apoio e envolvimento das comunidades étnicas à Cruz Vermelha dos países de origem envolvidos no conflito e a reivindicação dos políticos e intelectuais pelo fim das escolas étnicas em favor da nacionalização do ensino.

O jornal Diário da Tarde de Curitiba, após 1915 passou a defender a nacionalização do ensino, ou seja, a obrigatoriedade de o ensino ser ministrado em língua nacional e a adoção do Programa Oficial de Ensino em todas as escolas do estado (DIARIO DA TARDE, 04 agosto de 1915). Para os editores deste jornal, a escola era o melhor espaço para inserir a juventude na comunidade nacional, ou seja, nacionalizar a juventude pelo ensino. Propunha a fiscalização do Estado para garantir o cumprimento da legislação escolar ${ }^{5}$ (DIÁRIO DA TARDE, 11 de setembro de 1916; 28 de setembro de 1916, 18 de março de 1918). No artigo 'Instrução Pública', assinado por V. de Souza, relatava que o Uruguai e a Argentina que uniformizaram o ensino em seus países, em 1916. O autor propunha que no Brasil também se adotassem medidas para homogeneizar o ensino, especialmente com um programa escolar único, livros didáticos e que as escolas particulares fossem controladas pelo Estado (DIÁRIO DA TARDE, 28 de setembro de 1916).

A língua enquanto instrumento de nacionalização da população ganhou destaque nos discursos e falas de intelectuais (como Indio Paraguassu e Gastão Faria) e autoridades, nas páginas do jornal Diário da Tarde. Assim, em 1918, o Presidente do estado do Paraná, Afonso Camargo, manifestou-se sobre o tema, demonstrando que a legislação era pouco eficaz.

\begin{abstract}
A atual organização, considerando obrigatória a cadeira de português nas escolas estrangeiras, absolutamente não nos levará ao fim colminado (...) É tempo de inverter o atual sistema, isto é, em vez de ser obrigatória a Cadeira de língua portuguesa nas escolas estrangeiras, devemos generalizar a obrigatoriedade a todas as disciplinas, as quais o aluno só aprenderá se conhecer a língua vernácula (...) (DIÁRIO DA TARDE, 07 de fevereiro de 1918).
\end{abstract}

Após esta publicação, o Deputado Hugo Simas, apresentou na Assembleia Legislativa um projeto de lei para nacionalizar o ensino e o fechamento das escolas cujo ensino não era ministrado em Língua Portuguesa. Em nível nacional, em 1915 o Deputado Barbosa Lima apresentou projeto no mesmo sentido, indicando que todas as escolas estrangeiras, subvencionadas ou não deveriam ensinar em língua portuguesa (DIÁRIO DA TARDE, 04 de agosto de 1915). A imprensa divulgava o ideário nacionalista 
que fazia parte dos discursos de políticos e intelectuais do Paraná, nas primeiras décadas do século XX, mas, em virtude da Guerra, a imprensa dirigiu a maioria das matérias à comunidade alemã.

Nos anos de 1917 e 1918, a imprensa também registrava que a comunidade teuto brasileira tinha poder político e econômico, citando os Deputados Estaduais teutobrasileiros Nicolau Mäder e Bertholdo Hauer. Ao mesmo tempo, denunciava que haviam no Paraná escolas subvencionadas pelo governo alemão e que nos clubes alemães de Curitiba não se falava português (DIÁRIO DA TARDE, 18 de abril de 1917). Isto demonstrava as tensões causadas pela guerra reverberavam nas relações político-sociais desta comunidade com a elite local, especialmente sobre a necessidade de inserção das comunidades étnicas à sociedade brasileira.

Há uma imbricação entre o clamor pela nacionalização do ensino que se manifestava na imprensa, na Assembleia Legislativa e o recrudescimento da legislação e na fiscalização às escolas para que estas efetivamente nacionalizassem a infância. No ano de 1918, quando entrou em vigor o Decreto no 1775 de 03 de abril de 1918, que determinou a obrigatoriedade do ensino da Língua Portuguesa em todas as escolas paranaenses o processo de nacionalização do ensino evidenciava um pensamento já consolidado sobre a ameaça estrangeira e a necessidade de enfraquecer a ação educativa dos imigrantes e seus descendentes.

\section{A INSTITUCIONALIZAÇÃO DAS ESCOLAS SUBVENCIONADAS FEDERAIS E O PAPEL DA FISCALIZAÇÃO ESCOLAR.}

O Decreto no 13.014 de 04 de maio de 1918 promulgado pelo governo de Venceslau Brás Pereira Gomes instituiu as Escolas Subvencionadas Federais, com o objetivo de ampliar a nacionalização do ensino. Por meio de subsídios pretendia-se o fortalecimento e expansão da escola primária garantindo a disseminação da Língua Portuguesa especialmente nas regiões de forte colonização estrangeira no Sul do país.

De forma compartilhada, Estados e União deveriam empreender esforços para a disseminação do ensino da língua nacional e da história do Brasil, conforme orientava aquela legislação:

Art. $1^{\circ}$ O Governo Federal auxiliará com a quantia de 1:800\$ annuaes a manutenção de cada escola fundada pelos governos dos Estados, depois da publicação do presente decreto, e destinadas, precipuamente, ao ensino da lingua portugueza e da geographia e historia do Brasil, em municípios constituídos por antigas colônias de europeus, hoje emancipadas.

Art. $2^{\circ}$ Um inspector, nomeado, em comissão, pelo ministro da Justiça e Negocios Interiores, visitará as escolas subvencionadas, e, em relatorio trimensaes, dará o seu parecer, circunstanciado, sobre a efficacia ou deficiência do ensino ministrado nos novos institutos (BRASIL, 1918, p.1). 
RENK, V. E.; MASCHIO, E. C. F.

Os investimentos pesados da União para que os estados pudessem ampliar a escolarização dos filhos de imigrantes nos estados do Sul, continuaram no ano seguinte a publicação do decreto. Em janeiro de 1919 a Lei n 3.674 que fixava as despesas gerais da Republica para o exercício daquele ano, determinava que:

Art. 18. Fica o Poder Executivo autorizado a manter, durante o anno de 1919, os serviços creados pelo decreto n. 13.014, de 4 de maio de 1918, como auxilio á nacionalização do ensino primario nos Estados do Rio Frande do Sul, Santa Catharina e Paraná. § $1^{\circ} \mathrm{O}$ auxilio será dado na proporção das escolas subvencionadas no corrente anno, em cada um dos citados Estados, e mais a sessenta, que poderão ser acrescidas no proximo exercicio, sendo a subvenção de vinte para cada Estado. $\S 2 \circ$ Para os fins supra referidos fica aberto o credito de 869:025\$000 (BRASIL, 1919, p. 5).

Para fazer valer o que determinava o Decreto Federal no 13.014 de 04 de maio de 1918 instituiu-se uma importante rede de fiscalização escolar. Da mesma forma, para regular a concessão de auxílios as Escolas Subvencionadas Federais nos três estados, foi publicada no dia 5 de junho daquele mesmo ano algumas orientações sobre como se deveria proceder a fiscalização dessas escolas. Assim, a inspeção foi o ponto central da política que garantia a manutenção das Escolas Subvencionadas Federais. Os inspetores escolares federais fiscalizavam tanto os professores subvencionados, como os governos estaduais. Estes tinham o poder de propor, reclamar, autorizar e desautorizar a abertura, transferência ou o fechamento de escolas, bem como, a remoção dos professores. Além disso, orientavam os professores na escolha e na aplicação dos métodos a fim de garantir o sucesso com o ensino da Língua Portuguesa.

Em março de 1919, o Ministério da Justiça e Negócios Interiores, Urbano Santos da Costa Araújo, enviou um ofício reforçando o papel fiscalizador dos inspetores federal nos três estados sulistas. O documento foi publicado no jornal $A$ República e trazia o conteúdo do seguinte teor:

Para vosso conhecimento e devido effeitos declaro-vos: $1^{\circ}$ que o vencimento mensal dos professores das Escolas Subvencionadas não podem ser inferior a $150 \$$, visto que a esse fim se destina, principalmente, o auxílio prestado pelo governo da União na conformidade do art. $1^{\circ}$ do decreto $n^{\circ} .13 .014$ de 04 de maio de 1918. $2^{\circ}$ que, de accordo com o aludido dispositivo não podem ser subvencionados estabelecimentos que já existiam na data da promulgação do citado decreto. $3^{\circ}$ que não deve ser paga a subvenção correspondente às escolas ainda não providas ou que não tenham professor em exercício. $4^{\circ}$. Que, é vista do espírito do decreto $n^{\circ} 13.014$, o ensino nas Escolas Subvencionadas não pode ser confiado a estrangeiros. $5^{\circ}$ que, finalmente decisivo, como sempre, exigir observância do decreto $n^{\circ} 13.014$ e das instruções de 5 de junho de 1918, para que a subvenção se applique proveitosamente e de modo que corresponda às intenções do governo federal (A REPÙBLICA, 1919, p. 1).

Inter-Ação, Goiânia, v.46, n.2, p. 502-522, maio/ago. 2021. Disponível em: <http://dx.doi.org/10.5216/ia.v46i2.67767>. 
Entre os aspectos a serem observados pelos inspetores escolares federais estava a localização dessas escolas. Era necessário garantir que as Escolas Subvencionadas Federais fossem criadas em locais onde existisse a real necessidade da educação nacional, em função da significativa presença de crianças estrangeiras ou mesmo brasileiras de pertencimento étnico estrangeiro.

A transferência da Escola Subvencionada Federal da localidade de Santa Quitéria para a da colônia italiana Dantas, região da Água Verde ocorreu mesmo após a reclamação do Inspetor Subvencionado Federal Victor de Sá Barreto ao Diretor da Instrução Pública Dr. Manoel de Oliveira Franco. Ao verificar que uma única colônia passaria a concentrar três Escolas Subvencionadas Federais, além de outras escolas públicas elementares já existentes mantidas com o erário estadual, o inspetor tentou impedir a ação (PARANÁ, 1919, p. 73). Mesmo assim, a transferência foi efetuada e a região da Santa Quitéria ficou sem escola alguma.

Atuando nessa mesma perspectiva, no dia 05 de setembro do mesmo ano, o Inspetor Subvencionado Federal Victor de Sá Barreto, enviou um novo ofício ao Diretor da Instrução Pública com o intuito de reclamar que duas escolas subvencionadas pelo governo federal funcionavam no mesmo local na colônia Antônio Prado:

Tendo constatado que as professoras Angélica Reginatto e Celina Garcia Ferreira, nomeada com subvenção federal para a colônia Antônio Prado do município de Tamandaré, funcionam ali, num mesmo local, em estabelecimento vizinho, rogo ao governo do Estado prontas providências no sentido de serem estes isolados, um do outro, acordadamente de modo assim, a receberem instrucções todas as crianças, de origem estrangeira, em dita colônia existente (PARANÁ, 1919, p. 102).

Em resposta ao inspetor federal, o Diretor da Instrução Pública Dr. Manoel de Oliveira Franco comunicou no dia 09 de setembro, que tomou as providências necessárias para que as duas escolas fossem separadas, distante a pelo menos um quilômetro uma da outra.

No ano de 1919 havia na ex-colônia italiana Alfredo Chaves duas Escolas Subvencionadas Federais regidas respectivamente pelos professores Nilo Brandão e Emília Alvez Pereira de Jesus. Conforme os registros do Inspetor Escolar Federal Victor Sá Barreto efetuados após sua visita ao Estado do Paraná, direcionados ao Inspetor Geral do Ensino Cesar Pietro Martinez, era fundamental aproveitar uma daquelas escolas em outro ponto da região.

Acuso o recebimento do offício de V. Excia. datado de 17 deste a respeito persisto em solicitar a V. Excia. providências no sentido da nomeação da professora Da Emília Alves Pereira de Jesus para outro ponto fora da Villa, onde existam crianças de procedência extrangeira, que necessitem de instrucção. A colônia Alfredo Chaves é de fato a mesma Villa hoje sob a denominação de "Colombo". Mas estabelecimentos de ensino mantidos pela União, e de accordo com os actos federais reguladores do subsídio do Estado, não podem ser 
RENK, V. E.; MASCHIO, E. C. F.

localisados em centros assim, como digo, onde funcionam outros a cargo deste (PARANÁ, 1919, p. 56).

A região central daquela ex-colônia já tomava ares de cidade. Transformada em município no ano de 1890, a sede da ex-colônia contava com um número maior de escolas públicas elementares que apresentavam um número elevado de matrículas. Ademais, o inspetor reforçava a tese de que as Escolas Subvencionadas Federais deveriam ser instaladas em regiões onde o idioma nacional fosse ignoto. Ou mesmo, em função das distâncias, onde houvesse maior dificuldade das famílias estrangeiras assimilar os costumes brasileiros. Esse cenário facilmente encontrado bem longe dos centros urbanos.

A suspenção da regência da professora Emília Alvez Pereira de Jesus na Escola Subvencionada Federal na região central da ex-colônia Alfredo Chaves foi efetuada pelo Inspetor Escolar Federal Victor Sá Barreto no dia 17 de fevereiro de 1920 (PARANÁ, 1920, p. 103). Dois anos depois, uma nova Escola Subvencionada Federal foi aberta na região do Atuba, um bairro do então município de Colombo, ex-colônia italiana de Alfredo Chaves. Apesar dos esforços em disseminar a educação nacional, especialmente o ensino da Língua Portuguesa, a escola apresentava uma frequência de apenas 20 alunos, a grande maioria, brasileiros nenhum italiano e apenas dois alunos de origem alemã (PARANÁ, 1922, p. 3). Isso demostra que a política de nacionalização do estado brasileiro muito mais do que assimilar o estrangeiro, possibilitou preencher as lacunas deixadas pela falta de escolas elementares públicas nas regiões rurais do sul do país.

Em agosto de 1921 Candido Natividade da Silva assumiu a função de inspetor escolar federal no lugar de Victor Sá Barreto. Em um extenso relatório publicado no dia 17 de novembro de 1921 no jornal $A$ República, o inspetor descrevia as escolas inspecionadas durante o trimestre de julho a setembro daquele ano. De acordo com o documento existiam 116 Escolas Subvencionadas Federais em funcionamento com um total de matrículas de 4.201 e 3.215 de frequência, sendo 1.896 meninas e 1.319 meninos. A média de alunos matriculados por turma era de 37 , e 22 a média de frequência. Os números detalhados da quantidade de alunos por escola discriminados nos relatórios dos inspetores escolares federais se tornavam uma informação fundamental, pois somente assim o governo poderia avaliar o alcance da subvenção ou a necessidade de redimensionar os subsídios para outras regiões.

Além da fiscalização dos inspetores federais, as escolas subvencionadas eram submetidas às intervenções dos inspetores estaduais. Dentre os inúmeros registros inspetoriais localizados, ressalta-se como exemplo, o da escola da região colonial italiana de Água Verde. Ao iniciar o ano letivo de 1923, a escola recebeu a visita do Subinspetor Escolar José Busnardo e do Inspetor Escolar Nicephoro Modesto Falarz. Seguindo os procedimentos que buscavam fiscalizar, orientar e corrigir o encaminhamento das aulas se esse fosse o caso, os inspetores declararam não ter encontrado a escola em boas condições, apesar da elevada e satisfatória matrícula e frequência (PARANÁ, 1923, p.129).

A necessidade de fiscalizar, vigiar e controlar o ensino por meio dos inspetores escolares foram reforçadas na década de 1920, na gestão do Diretor da Inspetoria Geral do Ensino Cesar Prieto Martinez. A estrutura da inspetoria de ensino paranaense passou a ser composta por inspetores escolares regionais, e por subinspetores de ensino que buscavam efetuar visitas sistematizadas às diversas localidades em que se encontrasse 
uma escola. Segundo Renk (2014, p. 146), conforme a fala de Martinez, "a inspeção foi o pivô em torno do qual o aparelho escolar se moveria". Por meio de relatórios detalhados, os inspetores e subinspetores informavam as condições das escolas e da comunidade, os números de matrícula e frequência, o trabalho dos professores e, principalmente, se o ensino da Língua Portuguesa era realmente efetuado. As escolas estrangeiras tiveram atenção especial das autoridades de ensino, pois eram consideradas prejudiciais porque 'desnacionalizavam a infância', estas escolas funcionam como se estivessem em território estrangeiro, a língua falada era a polonesa, a alemã ou italiana e a língua nacional era desconhecida (PARANÁ, 1920, p. 23).

Os relatórios dos subinspetores detalhavam o trabalho dos professores e a organização escolar: "a sala de aula é imprópria, o mobiliário reduz-se a dois bancos e uma grande mesa. O Professor é um bom agricultor e um mau professor" (PARANÁ, 1923, p. 39). No município de Prudentópolis, área de colonização eslava, o subinspetor relatava que em algumas Escolas Subvencionadas Federais, como as regidas pelos professores (as) Alexandre Kozecheu, Simão Kokurudzka, Michalina Hrycychyn, Maria Sauka, para citar algumas, ensinavam em língua estrangeira. Estes docentes apesar de serem brasileiros, mal falavam a língua nacional. O Subinspetor propunha o fechamento das escolas ou então a substituição do docente (PARANÁ, 1923).

As Escolas Subvencionadas Federais eram observadas de todos os lados. O olhar fiscalizador lançado sobre elas reiterava a obrigação em torno da consolidação dos objetivos do ensino. Assim, no âmbito do trabalho dos inspetores também cumpria informar ao Diretor e ao governo as licenças, remoções, fechamento e abertura das escolas. Mas, nem sempre os inspetores eram bem recebidos nas comunidades. Em 1923, o inspetor escolar foi mal recebido e hostilizado na Cidade de Marechal Mallet, área de colonização eslava. A justificativa governamental era pelo mal estar que as escolas étnicas causavam na sociedade (PARANÁ, 1923, p. 64).

A atuação dos inspetores escolares no exercício da autoridade também pode ser observada no reestabelecimento dos trabalhos escolares da Escola Subvencionada Federal de São Bráz, na colônia italiana de Santa Felicidade. No ínterim de cinco meses, foram realizadas muitas negociações até que uma professora pudesse assumir as aulas na escola. Depois do pedido de exoneração da professora subvencionada Olinda Paiva Velasquez em 25 de maio de 1921, os inspetores escolares estaduais propuseram duas outras professoras como substitutas. A primeira, a professora Fiodalice Ciscato, foi sugerida pelo Inspetor Geral do Ensino Cesar Prietro Martinez, em 25 de junho e apresentada ao inspetor federal como candidata apta para reger aquela escola.

De descendência italiana e moradora da região, Fiodalice Ciscato não possuía habilitação pela Escola Normal, e permaneceu na regência provisória da escola conforme a determinação do inspetor federal. Ele reconhecia que "a subvenção federal deve ser aproveitada para a escola de mais difícil provimento de preferencia, com professora normalista ou de concurso", mas, tendo em vista a dificuldade de encontrar professoras com esse perfil, acatou a proposição de Martinez, declarando que: "Esta Inspetoria já nomeou a cadeira em questão a vários professores normalistas e effectivos; a candidata apresentada tem interesse no logar e, portanto, permanecerá ali em proveito do ensino" (PARANÁ, 1921, p. 76). Não se sabe por quanto tempo àquela escola 
RENK, V. E.; MASCHIO, E. C. F.

permaneceu aberta, pois em 28 de setembro, o Subinspetor Escolar João de Deus Domingos apresentou ao Inspetor Geral do Ensino, Cesar Prieto Martinez, um requerimento dos moradores da região solicitando o provimento da cadeira subvencionada. Da parte do inspetor, propunha-se como professora Amélia Pichet da Silveira, a qual tomou posse, com a aprovação do inspetor federal, no dia 3 de novembro de 1921.

Os moradores de São Bráz, districto judiciário de Santa Felicidade, município de Curitiba, na sua totalidade descendentes de italianos pedem provimento de uma cadeira para a educação de seus filhos, para o que já construíram um salão apropriado. Proponho a V. Ex. D. Amélia Pichet da Silveira para professora Federal dessa localidade (PARANÁ, 1921, p. 129).

Além de gerir o provimento das escolas, os inspetores escolares também se ocupavam das aprovações quanto as remoções, licenças e transferências. Em 1930, o trabalho dos inspetores foi decisivo no processo de transferência de professoras entre as escolas públicas. O Subinspetor Escolar José Busnardo participou das decisões quanto as remoções solicitadas pelas professoras das escolas das colônias italianas de Santa Felicidade e São Nicolau, apresentando ao Diretor da Instrução Pública os aspectos positivos, negativos e as consequências das remoções entre as escolas:

Designado por V. Exa. para syndicar da conveniência para o ensino com a remoção das professoras das escolas de Santa Felicidade e São Nicolao, neste município, respectivamente o cargo das professoras, normalista, sem concurso Cecília Nogarolli, subvencionada federal, Helena Nogarolli subvencionada federal, de categoria effectiva, Claudemira Marinho, para aquellas localidades me transportei no dia 2 do corrente. Após ouvir muitos alunos matriculados nas referidas escolas, após estudar as necessidades dos mesmos e a conveniência do ensino relativamente à distância, localização e residência dos alunos e respectivas escolas; após verificar a matrícula, a frequência e as médias diária e mensal de cada escola; após, finalmente, ouvir os motivos e alegações principalmente da professora Helena Nogarolli, constatei o nenhum resultado positivo para o ensino, quer com a remoção, quer com a transferência de qualquer das candidatas indicadas, conforme poderá V. Exa. Julgar. A escola de São Nicolao tem 37 alumnos matriculados com uma presença média de 25 e a de Santa Felicidade, com dois períodos, possue a matrícula de 69 alumnos com um comparecimento diário de 50 alumnos em média. Portanto, a primeira escola não comporta duas professoras e a matrícula da segunda é excessiva para uma só regente. Acresce, ainda, que a sala onde funcionam as escolas das duas professoras, irmãs Nogarolli, é ampla, espaçosa, bem ventilada e com capacidade para receber mais de 80 alumnos em dois períodos, pois para tal fim foi mandada construir, ao passo que, a escola da professora Marinho funciona na sala de jantar, pequenina e acanhada, dum prédio que é do Estado, onde residem pessoas da família da professora, com permissão de V. Exa., segundo declaração 


\begin{abstract}
da mesma. Transferir ou remover, portanto, uma das professoras ou as duas de Santa Felicidade para São Nicolao e vice-versa, segundo desejam as primeiras, creio não ser uma boa medida, pois além de não trazer nenhuma vantagem ao ensino e nenhum proveito à instrucção local, dada a natureza de cada prédio em relação aos seus requisitos e localização dos seus escolares, viria ainda acarretar serias dificuldades em relação às classes, há 3 mezes já formadas e afeitas às respectivas professoras, à instalação domiciliaria da professora de São Nicolao e o seu funcionamento na nova escola, com o mesmo mobiliário, o mesmo material didáctico e em sala comum com a outra professora (PARANÁ, 1930, p. 160).
\end{abstract}

Conforme descreve o registro do inspetor, as professoras subvencionadas Helena e Cecília Nogarolli solicitavam a remoção para a cadeira da escola isolada da colônia São Nicolau. Assim, a professora Claudemira, por consequência, assumiria a Escola Subvencionada Federal de Santa Felicidade. A troca de professoras atenderia as orientações da legislação sobre o provimento de professores para as escolas subvencionadas, uma vez que as professoras irmãs, Helena e Cecília, não possuíam habilitação e não foram admitidas por concurso, como havia sido a professora Claudemira. Depois de analisar as possibilidades para o atendimento, ou não, da rogativa, a decisão do inspetor foi manter a regência das três professoras em suas respectivas escolas.

Dessa forma, embora a legislação devesse ser seguida, bem como, a ordem hierárquica entre os inspetores, todos eles buscavam analisar, negociar e prover soluções levando em consideração as condições cotidianas das relações escolares, sempre com o intuito de garantir a organização e o bom funcionamento das Escolas Subvencionadas Federais.

\title{
CONSIDERAÇÕES FINAIS
}

Por se tratar de um tipo específico de escola pública elementar, as Escolas Subvencionadas Federais foram consideradas instituições chaves no processo de nacionalização do ensino. Foram criadas com o intuito de educar o filho do colono estrangeiro, propiciando-lhe o ensino da Língua Portuguesa, da História e da Geografia do país que os recebeu. Em função dos recursos financeiros dispendidos, essas instituições receberam atenção das autoridades de ensino, sendo os inspetores os principais agentes fiscalizadores. Estes indicavam a localização das escolas, exigiam a manutenção de matrículas e frequências avultadas, e cobravam do professor um bom desempenho no processo de alfabetização dos alunos. Apesar das especificidades que recobriam a organização dessas escolas, detalhadas pelos decretos que as regulamentavam, elas se prestaram ao atendimento da população escolar infantil não imigrante do estado do Paraná. Isso ocorreu porque uma parte considerável das Escolas Subvencionadas Federais foi implantada em regiões onde há muito tempo se reclamava a existência de uma escola elementar pública. 
RENK, V. E.; MASCHIO, E. C. F.

O rigor da fiscalização aplicado nas visitas e nas formas de controle marcou o cotidiano do trabalho desenvolvido pelos inspetores escolares. Não obstante, as relações de poder estabelecidas pelas escalas hierárquicas do sistema de fiscalização federal e estadual, colocaram em evidencia as disputas dos inspetores junto as Escolas Subvencionadas Federais. Padecendo dos mesmos problemas, essas escolas foram absorvidas pelo sistema de ensino primário vigente no estado. Embora estivessem pautadas pelos contundentes discursos de nacionalização e recebessem subvenção federal, elas organizaram seu cotidiano com aquilo que dispunham. Sobre o olhar dos inspetores, as Escolas Subvencionadas Federais foram impelidas pelos atos que ora convergiam, ora eram divergentes, porém - até culminar o processo compulsório de nacionalização do ensino em 1938 - sempre movidos pela negociação entre as autoridades do ensino e a comunidade imigrante.

Artigo recebido em: 17/02/2021

Aprovado para publicação em: 07/06/2021

SCHOOL SUBSIDY IN PARANÁ AND THE NATIONALIZATION OF EDUCATION IN IMMIGRATION AREAS (1899-1938)

ABSTRACT: Analyzes the importance of state and federal school subsidies in the organization of the primary public school and nationalization of education in Paraná. The years 1899 to 1938 representing the period of discussions on the obligation of teaching the Portuguese language in subsidized and private schools, due to the possible threats posed by the ethnic school organization, until the compulsory nationalization of education. There was a dispute over the school space between the state government with ethnic communities and the acting of the federal government. The historical method guides theoretical methodological analysis, whose sources are official documents such as: educational legislation, government reports, requirements, regional newspapers. Cultural History sheds light on the documentary corpus. Sources show that the resources of the school subsidies were directed to elementary schools, but were also intended for ethnic schools, privileged spaces for the formation of the ideal Brazilian childhood. However, the organisation of such schools occurred in a negotiated manner between educational authorities and ethnic community to nationalize childhood, but also with the possibilities to keep ethnic identity.

KEYWORDS: Ethnic Schools. School Subsidies. Nationalization of Education.

LA SUBVENCIÓN ESCOLAR EN PARANÁ Y LA NACIONALIZACIÓN DE LA ENSEÑANZA EN LAS ÁREAS DE INMIGRACIÓN (1899-1938)

RESUMEN: Se analiza la importancia de los subsidios escolares estatales y federales en la organización de la escuela pública primaria y la nacionalización de la educación en Paraná. Los años 1899 a 1938 representan el período de discusiones sobre la obligatoriedad de la enseñanza

Inter-Ação, Goiânia, v.46, n.2, p. 502-522, maio/ago. 2021. Disponível em: <http://dx.doi.org/10.5216/ia.v46i2.67767>. 
de la lengua portuguesa en escuelas subvencionadas y privadas, debido a las posibles amenazas provocadas por la organización étnica escolar, hasta la nacionalización obligatoria de la educación. Había una disputa sobre el espacio escolar entre el gobierno estatal y las comunidades étnicas y la actuación del gobierno federal. El método histórico orienta el análisis teórico metodológico, cuyas fuentes son los documentos oficiales como: legislación educativa, informes de gobierno, oficios, requerimientos, periódicos de circulación regional. La historia cultural lanza luz sobre el corpus documental. Las fuentes revelan que los recursos de la subvención escolar debían ser dirigidos a las escuelas elementales, pero también fueron destinados a las escuelas étnicas, espacios privilegiados para la formación de la infancia brasileña ideal. Sin embargo, la organización de estas escuelas se llevó a cabo de una manera negociada entre las autoridades educativas y la comunidad étnica para nacionalizar la infancia, pero también dentro de las posibilidades de mantener la identidad étnica.

PALABRAS CLAVE: Escuelas étnicas; Subvención Escolar; Nacionalización de la Enseñanza.

\section{NOTAS}

1 - As comunidades étnicas não consideravam as escolas étnicas que recebiam a subvenção como escolas públicas, e, neste documento, as autoridades também as consideram como escolas estrangeiras.

2 - Para as escolas étnicas, o governo do Paraná usa o termo escolas estrangeiras. Podiam ser escolas em que o diretor era brasileiro (nato ou naturalizado) e o corpo docente estrangeiro, ou mesmo o diretor podia ser brasileiro e a escola subvencionada por governo estrangeiro ou mantida por associação étnica. Para as autoridades o pertencimento étnico era entendido como estrangeiro, mesmo que nascido no Brasil.

3 - O Jornal Der Kompass (A Bússola) era publicado desde 1902 em língua alemã com caracteres góticos, pelos padres franciscanos de Curitiba. Circulou no Paraná, Santa Catarina e São Paulo até 1941.

4 - Sobre o 'perigo alemão', inúmeros políticos e intelectuais alertavam sobre a possibilidade da Alemanha anexar as colônias alemãs além da Europa, para formar a Grande Alemanha (Grossdeutschland). Para saber mais ver BREPOHL DE MAGALHÃES (1993).

5 - As seguintes Legislações Educacionais pugnavam pelo ensino em língua nacional nas escolas do Paraná: Lei Estadual n. 723 de 03 de abril de 1907, Lei 894 de 19 de abril de 1909, Código de Ensino de 1917, Lei 2005 de 09 de abril de 1920 e Lei 2.157 de 1922.

\section{FONTES}

BRASIL. Lei n 3.674 de 7 de janeiro de 1919. Fixa a despesa geral da República dos Estados Unidos do Brasil para o exercício de 1919. Diário Oficial. Estados Unidos do Brasil. República Federal. 1919.

BRASIL. Decreto Federal no. 13.014, de 4 de maio de 1918. Diário Oficial. Estados Unidos do Brasil. República Federal. 1918. 
RENK, V. E.; MASCHIO, E. C. F.

PARANÁ. Código de Ensino do Estado do Paraná, Decreto no 17 de 09 de janeiro de 1917. Curityba: Typ. d'A República, 1917.

PARANÁ. Departamento Estadual de Arquivo Público. Ofício. Livro 1745. 1919, p. 73.

PARANÁ. Departamento Estadual de Arquivo Público. Ofício. Livro 1753. 1919, p. 56.

PARANÁ. Departamento Estadual de Arquivo Público. Ofício. Livro 1759, 1919, p. 102.

PARANÁ. Departamento Estadual de Arquivo Público. Ofício. Livro 1780. 1920, p. 103.

PARANÁ. Relatório apresentado ao Exmo. Sr. Dr. Secretário Geral de Estado pelo Professor Cesar Prieto Martinez Inspetor Geral do Ensino. Typ. Da Penitenciária do Estado: Curityba, 1920.

PARANÁ. Departamento Estadual de Arquivo Público. Ofício. Livro 1831, 1921, p. 91, 125.

PARANÁ. Departamento Estadual de Arquivo Público. Requerimento. Livro 1841. 1921, p. 227.

PARANÁ. Departamento Estadual de Arquivo Público. Requerimento. Livro 1844. 1921, p. 183.

PARANÁ. Departamento Estadual de Arquivo Público. Requerimento. Livro 1856. 1921, p. 70, 76.

PARANÁ. Departamento Estadual de Arquivo Público. Requerimento. Livro 1859. 1921, p. 129.

PARANÁ. Relatório de Governo, apresentado pelo Secretário de Estado dos Negócios do Interior, Justiça e Instrução Pública Claudino Rogoberto Ferreira dos Santos. Curityba, Typ. d' A Republica, 1913.

PARANÁ. Departamento Estadual de Arquivo Público. Ofício. Livro n. 26, 1912, p. 42.

PARANÁ. Departamento Estadual de Arquivo Público. Requerimento, Livro n. 10, 1913, p. 19.

PARANÁ. Relatório apresentado ao Exmo. Sr. Dr. Secretário Geral de Estado pelo Professor Cesar Prieto Martinez, Inspetor Geral do Ensino. Typ. da Penitenciária do Estado: Curityba, 1921.

PARANÁ. Departamento Estadual de Arquivo Público. Ofício. Livro 1787, 1922, p. 58.

PARANÁ. Departamento Estadual de Arquivo Público. Ofício. Livro 1881. 1922, p. 3. 
PARANÁ. Relatório de Inspeção das Escolas Subvencionadas no Paraná, 1922, p. 51.

PARANÁ. Relatório apresentado ao Inspetor Geral do Ensino Cesar Prieto Martinez pelo professor João Rodrigues subinspetor no ano de 1922. Typ. da Penitenciária do Estado: Curityba, 1922.

PARANÁ. Departamento Estadual de Arquivo Público. Ofício. Livro 1887, 1923, p. 88.

PARANÁ. Departamento Estadual de Arquivo Público. Ofício. Livro 1952, 1923, p.129.

PARANÁ. Relatório de Governo apresentado ao Secretário Geral do Estado, pelo Inspetor Geral da Instrução, Professor César Prieto Martinez, Inspetor Geral do Ensino. Curityba: Penitenciária do Estado, 1923.

PARANÁ. Departamento Estadual de Arquivo Público. Ofício. Livro 2313, 1930, p. 160161.

PARANÁ. Lei n. 17 de 14 de setembro de 1854. Cria as cadeiras de latim, francês e inglês, na capital da Provincia e também aborda sobre a subvenção escolar, entre outras. In. MIGUEL, M.E.B.; MARTIN, S. D. Coletânea da Documentação Educacional Paranaense no período 1854-1889. Brasília: INEP/SBHE, 2004, p.34.

PARANÁ. Lei. n. 365 de 11 de abril de 1900. Organiza o sistema estadual e ensino. Prevê que particulares podem manter escolas. Curityba: Departamento Estadual de Arquivo Público. Legislação Estadual, 1900, p. 54-59.

PARANÁ. Lei n. 894, de 19 de abril de 1909. Organiza o sistema estadual de ensino. Leis, Decretos e Regulamentos do Estado do Paraná. Curityba: Departamento Estadual de Arquivo Público, 1909, p.73-105.

PARANÁ. Decreto no. 17 de 09 de janeiro de 1917. Aprova o Código de Ensino do estado do Paraná. Colleção de Decretos e Regulamentos de 1917. Curityba: Tipografia D’A República, 1917, p. 9-91.

PARANÁ. Lei 2005, de 09 de abril de 1920. Código do Ensino. Regulamenta o Código de Educação do Paraná. Curityba: Typografia d'A República, 1920.

PARANÁ. Lei 2.157, de 08 de abril de 1922. Código de Ensino. Regulamenta o Código de Educação do Paraná. Curityba: Typografia d'A República, 1922.

DER KOMPASS. O perigo alemão (tradução). Curitiba. Edição de 03 de novembro de 1906, p. 2. Arquivos do Colégio Bom Jesus, Curitiba. 
RENK, V. E.; MASCHIO, E. C. F.

JORNAL DIARIO DA TARDE. A obrigatoriedade do ensino de portuguez nas escolas estrangeiras. Curitiba, 04 de agosto de 1915, p. 1.

JORNAL DIARIO DA TARDE. Instrucção Pública. Curitiba, 11 de setembro de 1916, p. 1. JORNAL DIARIO DA TARDE. Instrucção Pública. Curitiba, 28 de setembro de 1916, p. 1. JORNAL DIARIO DA TARDE. O germanismo no Paraná. Curitiba: 18 de abril de 1917, p. 1. JORNAL DIARIO DA TARDE. O nacionalismo. Curitiba: 07 de fevereiro de 1918, p.1.

JORNAL DIARIO DA TARDE. Para que o Brazil pertença, de verdade aos brasileiros. Curitiba, 18 de março de 1918, p.2.

\section{REFERÊNCIAS}

BARROS, José D'Assunção. Fontes Históricas: Introdução aos seus usos historiográficos. Petrópolis: Vozes, 2019.

BREPOHL DE MAGALHÃES, Marionilde Dias. Alemanha, mãe pátria distante: utopia pangermanista no sul do Brasil. Tese (Doutorado em História) Campinas: UNICAMP, 1993.

CHARTIER, Roger. A História Cultural - Entre Práticas e Representações. Algés: Difusão Editorial, 2002.

DERRIDA, Jacques. Mal de Arquivo: uma impressão freudiana. Trad. Claudia de Moraes Rego. Rio de Janeiro: Relume Dumará, 2001.

LE GOFF, Jacques. História e memória. Campinas: Ed. da Unicamp, 2003.

FARGE, Arlette. O sabor do arquivo. São Paulo: Edusp, 2009.

NEGREIROS, Leandro Ribeiro; DIAS, Eduardo José Wense. A prática arquivística: os métodos da disciplina e os documentos tradicionais e contemporâneos. Perspectiva em Ciência da Informação. v. 13, n. 3, set/dez, 2008. p. 2-19.

MASCHIO, Elaine Catia Falcade. A nacionalização da infância imigrante nos discursos controversos da Assembleia Legislativa do Paraná entre os anos de 1899 a 1918. Anais eletrônicos do XVI Encontro Regional de História: Tempos de transição. Ponta Grossa: ANPUH PR, 2018. p. 1-10. 
MASCHIO, Elaine Catia Falcade. A escolarização dos imigrantes e de seus descendentes nas colônias italianas de Curitiba: entre táticas e estratégias (18751930) Tese de doutorado. Curitiba: UFPR, 2012. p. 341.

MIGUEL, Maria Elisabeth Blanck; MARTIN, Sonia Dorotea. Coletânea da Documentação Educacional Paranaense no período 1854-1889. Brasília: INEP/SBHE, 2004.

OLIVEIRA, Lúcia Lippi. A questão nacional na Primeira República. São Paulo: Brasiliense, 1990.

QUADROS, Claudemir de. (Org.). Uma gota amarga: itinerários da nacionalização do ensino no Brasil. 1ª. ed. Santa Maria: UFSM, 2014.

RENK, Valquíria Elita. As escolas étnicas polonesas e ucranianas no Paraná. Curitiba: Appris, 2014.

RENK, Valquíria Elita. A educação dos imigrantes alemães católicos em Curitiba. Curitiba: Editora Champagnat, 2004.

RENK, Valquíria Elita. Aprendi falar português na escola! O processo de nacionalização das escolas étnicas polonesas e ucranianas no Paraná. Tese (Doutorado em Educação). Curitiba: UFPR, 2009.

RINKE, Stefan. Alemanha e Brasil, 1870-1945: uma relação entre espaços. História, Ciências, Saúde Manguinhos. vol. 21 no.1 Rio de Janeiro Jan./Mar. 2014. p. 1-17.

SOUZA, Rosa Fátima de. História da Cultura Material Escolar: um balanço inicial. In: BENCOSTTA, Marcus Levy. Culturas escolares, saberes e práticas educativas: itinerários históricos. São Paulo: Cortez, 2007. p. 163-189.

VEYNE, Paul. Como se escreve a história. Lisboa: Edições 70, 2008.

Elaine Cátia Falcade Maschio: Doutora e Mestre em Educação pela Universidade Federal do Paraná (UFPR). Licenciada em Pedagogia pela Universidade Federal do Paraná (UFPR). Realizou Estágio de Pós-Doutorado em Educação na Universidade de Caxias do Sul (UCS). Tem experiência na área da Educação, atuando ao longo dos anos como professora e pedagoga no Ensino Fundamental, Médio, Superior, Lato Sensu e Stricto Sensu nas modalidades presencial e à distância, da rede pública e particular de ensino. Realiza pesquisas sobre os Processos de Escolarização e a Cultura Escolar nas Colônias Italianas do Paraná, sobre a História da Infância Imigrante Italiana e de seus Descendentes, e sobre Práticas Pedagógicas e Tecnologias Educacionais.

Orcid: https://orcid.org/0000-0001-5543-201X

E-mail: elainefalcade@uol.com.br 
RENK, V. E.; MASCHIO, E. C. F.

VAlquírIA Elita RenK: Graduada em Geografia (Licenciatura e Bacharelado) pela Universidade Federal do Paraná (1985), Mestrado em Educação pela Pontifícia Universidade Católica do Paraná (2000), Doutorado em História da Educação pela Universidade Federal do Paraná UFPR (2009). Estágio de Pós Doutoramento no Programa de Pós Graduação em Educação na Universidade Federal do Paraná (2019). É Professora Titular da PUCPR, Professora Permanente do Mestrado em Bioética (PUCPR) e do Mestrado em Direitos Humanos e Políticas Públicas (PUCPR). É líder do Grupo de Pesquisa Bioética e Educação, cadastrado no CNPQ. Pesquisa na área de Educação, nas interfaces com Bioética, Direitos Humanos, História da Educação e Saúde.

Orcid: https://orcid.org/0000-0002-2679-7471

E-mail:valquiria.renk@pucpr.br

Este periódico utiliza a licença Creative Commons Attribution 3.0, para periódicos de acesso aberto (Open Archives Initiative - OAI). 